\title{
The freedom to teach: Implications of the removal of Persepolis from Chicago schools
}

\begin{abstract}
Despite sometimes being viewed as inferior to other forms of literature, comic books and graphic novels are frequently used within the school curriculum. However, in March 2013, public schools in Chicago were instructed by the district authority to remove the well-respected graphic novel Persepolis from libraries and classrooms. Chicago Public Schools indicated that the ban would only be revoked once professional development guidelines for teachers had been produced to support the teaching of the text. This article examines the types of support which teachers may benefit from when teaching graphic novels, and Persepolis in particular, and questions whether the possible lack of such support justifies the removal of the text from schools.
\end{abstract}

Keywords: graphic novels, Persepolis, censorship, teaching, teacher training, education 


\section{The freedom to teach: Implications of the removal of Persepolis from Chicago schools}

\section{Introduction: Comics and censorship}

Censorship can be defined as "the suppression of ideas and information that certain persons-individuals, groups or government officials-find objectionable or dangerous" (ALA 2013). The link between comics and censorship is nothing new. Throughout their history, comics have been viewed as "the lowest rung of the cultural ladder" (Weiner 2003, 3), leaving the medium vulnerable to censorship attempts. Being on the margins, rather than in the mainstream of culture, they have long been viewed as objectionable or dangerous. Comics are still the subject of controversy in the second decade of the twenty-first century. For example, the graphic novel, The Color of Earth, was the second most challenged book of 2011 according to the American Library Association's Office of Intellectual Freedom. Other comic books which have recently faced challenges include Bone by Jeff Smith, Fun Home by Alison Bechdel and Sandman by Neil Gaiman to name but a few. Comics can become the target of censorship for a variety of reasons. Aspects of comics which can commonly make them the subject of challenge include: the text (for example offensive language), the images (for example, scenes including nudity, sexual acts or violence); or the overall theme (for example, content which is felt to be socially, racially or religiously offensive). Gerde and Spencer Foster (2007) argue that comics are an intelligent and outward looking media that can be used throughout many levels of education to highlight social issues. However, this can, in itself, can lead to problems. As Hammond points out, "reasons educators may be slow in their acceptance of graphic novels may be due to mature themes in some of them" (Hammond 2009, 56).

According to McNicol's study of censorship practices among school and children's librarians, graphic novels and manga were among the most problematic types of resource. Many librarians were unsure how to treat these and had tried to find a compromise which avoided confronting trickier issues, for example, to "bury them among the adult shelves" so students may find them and read them, but were not allowed to borrow them (McNicol 2005, 13). 
It is worth noting that a number of the controversies surrounding comics have resulted from particular books being promoted among age groups for which they were not originally intended, for example by shelving adult comics in the children's section of libraries or bookshops, as reported on the First Amendment Center website on 7 December, 2009. This points to a more pervasive problem, namely, a limited understanding and knowledge of comics and graphic novels among many librarians, booksellers and teachers who are not regular readers of the medium.

\section{The complexity of comics}

Comics have, therefore, frequently been the target of both direct and indirect forms of censorship. As suggested above, part of the explanation for this, may be the "lingering stigma that comics are low-value speech" referred to on the Comic Book Legal Defense Fund website (accessed 12 July 2013). However, comics may also be vulnerable to censorship because they can be interpreted in many different ways; they do not present a single, indisputable message, but instead rely on the reader to produce their own interpretation of the text and images. The nature of comics as a dual word-image medium continues to be widely debated. The following section attempts to briefly summarise the main issues as they relate to the teaching of comics in schools, and in particular, reactions to Persepolis. The approach outlined below is described in greater detail and with reference to wider contexts in McNicol and Weaver (2013) as well as in the sources cited.

As Hatfield acknowledges, "the kinds of mixed messages" comics send can be seen as a double-coded narrative which can prove a challenge for even the most experienced of readers. He further acknowledges that comics, "are always characterised by a plurality of messages. They are heterogeneous in form, involving the co-presence and interaction of various codes" (Hatfield 2005, 36). This means that comics need not have a single, clear message; on the contrary, they are often characterised by the presence of multiple messages.

This means that comics, as a medium, can place "a great demand on cognitive skills" (Chute, 2008). The way in which information is coded in comics can be highly complex. Readers are required to interpret not only text, but also images and must, therefore, negotiate two systems of codes which sometimes function 
independently, and at other times interact. As a hybrid word-image format, therefore, comics have "dual narrative tracks" (Chute, 2008) which require the reader to develop a number of strategies to make sense of the various possibilities presented.

This makes the role of the comic book reader a crucial one. A reader of comics must actively contribute to the negotiation of meaning; meaning does not reside in the text itself, but is created through the interaction of reader, image and text. The comic book reader has been described by McCloud as the author's "silent accomplice" and "equal partner in crime" (McCloud 1994, 68), thus comics require a substantial degree of reader participation for narrative interpretation, which fosters a form of interpretive intimacy. This active participation demonstrates Rosenblatt's (1994) transactional theory of reading, in which a literary work is conceived not as an object, but as an experience shaped by the reader under the guidance of the text. This guidance takes the form of clues (Allen, 1998) or reading instructions (Iser, 1989) provided by the author. Rosenblatt proposed that a "literary work exists in a live circuit set up between reader and text" (Rosenblatt 1994, 25). In reading a comic, however, the situation is more complex as there are three components: reader, written text and visual language. The reader creates an overall meaning by relating both the words and images to their own experiences. This individualises each response. As a result, there is no single 'correct' or absolute meaning, but rather more or less equally valid alternative interpretations. Furthermore, for the reader meaning is not fixed, it can change during the course of reading and can be modified after the work has been read. The relationship between reader and text is therefore not a linear one; it can be thought of as a series of events.

Of course, the author can guide the reader, for example, encouraging them to view an image in a certain way according to features of the layout, such as looking up at something to make it appear oppressive or frightening. However, even when such suggestions are offered, the reader still has some latitude in the way in which they construct meaning from the image.

Critically for the reading of historical texts and autobiographies, such as Persepolis, the reader is also able to exercise control over time when reading a comic. Comparing comics to film and television, Morrison explains, "The pace of a film or television show was dictated by its director. The comics allowed the 
reader to direct his or her own experience of the story" in doing so, "the images could be slowed down, rewound, fast-forwarded and studied in detail" (Morrison, $2001,117)$. Comics can show multiple perspectives within the same frame, thus presenting the reader with images from past and present simultaneously.

According to El Refaie comics are, "well suited to the task of conveying subjective time, since many of its formal features follow patterns that reflect the way memory itself works" (El Rafaie, 2010, 281). Chute describes how, "Comics can express life stories, especially traumatic ones, powerfully because it makes literal the presence of the past by disrupting spatial and temporal conventions to overlay or palimpsest past and present" (Chute, 2011, 109). Similarly, McCloud illustrates how, in comics, past and future are not simply "memories" and "possibilities", but are "real and visible and all around us!" (McCloud, 1994, 104). Comics allow the reader to shift backwards and forwards through time as their eyes drift away from the 'now' panel to those preceding or succeeding.

Despite such possibilities to manipulate time, comics are, of course, a series of static images or "visual fragments" (Greonsteen 2007) which omit far more visual information than they include.. Key to the analysis of comics, therefore, is Iser's notion of 'gaps' in the text, absences of connections that readers must fill in order to make sense of the text. In comics, these 'gaps' take the particularly striking form of gutters between frames. Readers need to "read between the panels" (Brenner 2006, 125) in order to complete the narrative. Comics therefore possess and inherent "incompleteness" and "indeterminacy" which "urges readers to take up the constitutive act of interpretation" (Hatfield, 2005, xiii). It is the reader who decides what to include or omit based on a highly individual range of factors. As Iser (1989) describes, unlike the hypothetical Implied Reader, the Actual Reader may not fill the gaps and complete meaning in the text in the way in which the author intended. On the contrary, the Actual Reader should be allowed a degree of freedom in their interpretation of the text. Rather than a single version of the text, comics therefore present the reader with an array of interpretative options (Hammond 2009, 22).

Hatfield acknowledges that this freedom means that comics can seem "radically fragmented and unstable", but argues that this "tension" is their "great strength" (Hatfield 2005, 36). The tension Hatfield describes is created by the way in which various interpretative options "must be played against each other" 
(Hatfield 2005, 36) as readers make judgements and respond to the visual and textual messages of the comic. However, it is precisely this array of interpretative options and the lack of an unambiguous message which can sometimes lead to calls to censor comics.

\section{The teaching of comics}

Although comics are often perceived to be of lesser value than novels and purely word-based texts, comic books and graphic novels are frequently to be found within the school curriculum. In addition to more obviously applicable subjects such as languages and art, there has also been documented use of comics to teach history (Aiken, 2010), business studies (Gerde \& Foster, 2007), sociology (Hall \& Lucal, 1999) and science (Hosler and Boomer, 2011). There were attempts to bring comics into teaching practice as far back as the 1940s (Tilley, 2013), when a manual was created showing how comics related to the school curriculum in the United States (Hutchinson, 1949). But as Weiner and Syma claim, not entirely unreasonably, that "In the past 10 to 15 years, the use of sequential art in education has exploded" (Weiner \& Syma, p.1) not just in terms of number of publications, but also in the variety of topics. During this period, a range of materials have been produce to support teachers wishing to use comics within the classrooms. One example is Education Scotland's Graphic novels in the Curriculum in Scotland, an online resource aimed at supporting staff in both developing their knowledge of the comic/graphic novel medium and understanding its full potential in a classroom/leisure reading situation. Another of many examples is the Manga Shakespeare resources produced by the publisher SelfMadeHero and Promethean educational technology company. These focus on ways to teach the comics making use of new technology.

Are materials specifically to support the teaching of comics necessary? Although comics and graphic novels have grown as a subject of research in recent years, there is still relatively little research into the difficulties readers can experience in understanding this format (Hatfield, 2005). However, Pustz (1999) argued that the particular skills required to read comics successfully require training and experience and the mastery of these skills establishes "an audience of expert readers" of the comics format. The textual literacy skills required to make sense of a novel are not sufficient on their own; readers of comics require an overlapping, but distinct, skillset which also includes visual literacy skills. A 
knowledge of comics conventions or visual grammar (McCloud 1994), for example the difference between speech and thought bubbles and the use of streaking to indicate speed, is necessary to make sense of the information presented to the reader.

It is not just students who may require guidance and practice in order to interpret comics, teachers too may struggle, especially if they are not regular readers of the format themselves. Because comics are a more complex medium than they may first appear, those without regular experience of reading comics, and particularly less familiar genres such as manga, may look for support to help them make sense of the texts and also to find appropriate ways to develop the necessary skills, such as visual literacy, among their students.

\section{Persepolis and Chicago School Board}

Persepolis is a graphic novel which has been taught in many schools around the world since its publication in 2003. It is an autobiographical graphic novel by Marjane Satrapi depicting her childhood and early adult years in Iran during and after the Islamic revolution. It was originally published in French, but has been translated into more than forty languages. It has won awards within both the comic book and library worlds, including the Prix Alph'art Coup de Coeur at Angoulême, Prix du Lion in Belgium, YALSA (Young Adult Library Services Association) Best Books for Young Adults, School Library Journal Adult Books for Young Adults and the Prix France Info. Many of the themes covered echo those commonly found in young adult texts including coming of age, struggling with society's values, rebellion, and negotiating thresholds, but these take place within the less familiar context of Iranian history and culture. As Marji grows up, the Shah's regime is overthrown and the country experiences an Islamic Revolution and a war with Iraq.

It comes as little surprise to learn that Persepolis has caused controversy in Iran, as reported by AFP news agency on 14 February 2008, but much less expected was the reaction from Chicago Public Schools (CPS) in March 2013. On $13^{\text {th }}$ March, public schools in Chicago were instructed by the district authority to remove Persepolis from libraries and classrooms. Although the reason for this was not immediately clear, CPS later issued a statement to explain that the action was due to its "graphic language and images that are not appropriate for 
general use in the seventh grade curriculum". In particular, a letter from Barbara Byrd-Bennett, Chief Executive Officer of CPS which was reproduced on CPS website, sees CPS arguing that the book contained "powerful images of torture". Prior to this action, the book was not only permitted in schools, but was an instructional text in the CPS Literacy Content Framework (Common Core) Seventh Grade Toolset, a curriculum guide provided for teachers.

A host of free speech organisations, including the National Coalition Against Censorship, the Comic Book Defense Fund and the American Booksellers' Foundation for Free Expression attacked the restriction, coming together to write a joint letter to CPS. The American Library Association also voiced its "deep concern" in a separate letter reproduced on the Chicago Teachers' Union website, which described the directive as, "a heavy handed denial of students' rights to access information" which "smacks of censorship". Furthermore, the district's Head of School Libraries did not comply with the instructions from CPS, but instead issued a directive saying the book was, in fact, to remain on library shelves, in line with the library collection development policy.

Two days after the original directive, CPS backtracked to some extent, stating that Persepolis should only be removed from 7th grade (12-13 years) classrooms and not immediately prohibited in the classroom rooms of older students. If seventh-grade teachers had not yet taught the book, they were instructed not to do so and to remove any copies of the book from their classrooms.

Naturally, the actions of CPS immediately prompted a reaction, not just within the local community in Chicago, but also more widely in online discussions. In the discussions which followed the withdrawal of Persepolis, various reasons for the decision were suggested. On its website, the highly active and politicallyengaged Chicago Teachers' Union chose to frame the discussion in terms of social justice and political awareness, arguing that the book was viewed as dangerous by the district because it encourages young people to question existing structures and ideas, commenting:

"We understand why the district would be afraid of a book like this-- at a time when they are closing schools--because it's about questioning authority, class structures, racism and gender issues. There's even a part 
in the book where they are talking about blocking access to education. So we can see why the school district would be alarmed about students learning about these principles."

As the quote above indicates, local politics and ongoing debates around management decisions taken by CPS, as well as broader political issues, were closely linked to reactions to the decision within the immediate community.

Looking more widely, other commentators suggested that theinternational political context was significant. For example, Julian Darius' editorial on the Sequart Research and Literacy Organization blog argued that:

"The content in question has to do with torture. And torture has a political context, especially in America today."

In an email attempting to clarify the situation, reproduced on scribd.com, the Chief Executive of CPS described plans to "develop professional development guidelines, so that teachers can be trained to present this strong, but important, content" and explained that CPS was "also considering whether the book should be included, after appropriate teacher training, in the curriculum of eighth through tenth grades". Although most discussions observed online have centred around CPS's actions in removing the book from classrooms, the insistence that Persepolis should only be taught once teachers have received dedicated training is also a significant aspects of this event. Why did CPS believe that teachers need special training to enable them to deliver this particular text? What skills did they believe teachers lacked which would prevent them from teaching Persepolis to their students?

In the documents issued by CPS, the argument is made that Persepolis is not suitable for Grade 7 students, without guidance and support from a teacher. According to an article on Publishers' Weekly website on 15 March 2013, the aim of the proposed teacher training guide, according to the CPS, is to, "make sure that the message about inhumanity [is what] kids walk away with, not the images of someone with exposed body parts urinating on someone's back or someone's being tortured" and to ensure that students "have the background 
and maturity to appreciate the book" and providing support, "so the content of this book can be accessed".

There are valid reasons why additional support may be beneficial for teachers using Persepolis within the classroom. For example, Persepolis deals with many complex political and social issues in a country whose history is likely to be unfamiliar to both students and teachers.. As Richards and Williams point out, the Marji's "examples of adolescent resistance to social norms resonate with students", yet the social context, and potential consequences, of her challenges are unfamiliar. Furthermore, the trainee teachers Spangler engaged with felt “their own ignorance of Iran's culture and history had hindered their full appreciation" of the text (Spangler, 2010, 65). So further information about the context of the story may lead to a deeper, and more rewarding, reading. However, this prompts concerns about how to ensure that the background information provided is politically neutral. When reading a work of fiction, even one based on real events, readers are expected to question what they read and are aware that not every detail of a story may be factually accurate; they appreciate that events may be presented from the perspective of a particular character for instance. This is not the case with teaching or study notes. Teachers or students using such materials expect the information contained to be accurate and unbiased. It is, therefore, crucial that care is taken to ensure that the nature of any information provided to support teachers or students does not present a single political viewpoint, but rather opens up the comic further to the reader by deepening their appreciation of the variety of ways in which the story might be understood and how events are seen by the various characters in the graphic novel.

It is interesting to note the wide range of responses to the withdrawal of Persepolis. These reactions, in themselves, indicate the multiplicity of readings and the ways in which commentators can make a number of diverse connections between a story about Iran in the early 1980s and situations in the United States more than thirty years later. Students should be encouraged to explore these connections for themselves and assess the validity, or otherwise, of possible interpretations based on their own background, experiences and beliefs. Resources which support students and teaching in conducting this interpretative and reflective activity would, indeed, be valuable. 
Of course, regardless of its subject matter, Persepolis is a comic book, a format which may not be familiar to many teachers and students as a classroom text. Comics have a deceptive simplicity. As Eisner admitted, the act of interpreting this medium is "more demanding of diverse skills and intellect than either I or my contemporaries fully appreciated" $(1985,6)$. Not all students will be familiar with comics which deal with serious issues, and not all teachers will be familiar with methods of studying comics. Although there is limited rigorous research into teachers' attitudes towards comics and graphic novels, traditionally, they have been viewed as more suited to less able students who might struggle with more text-heavy resources. Although, more recently the use of comics and graphic novels in the classroom with students across the ability range has become a more commonplace activity, it is still not a format which all teachers regularly engage with. So, providing more support for teachers to use comics and graphic novels such as Persepolis in the classroom, including ways to teach the visual and textual literacy skills required to read comics, is welcome. The plethora of resources currently available to support the teaching of comics indicates the demand for, and perceived value of, this type of teaching support. Some examples include: Comics in the Classroom ${ }^{1}$ and Teaching Comics ${ }^{2}$. However, it is crucial that the nature of this support respects the inherent ambiguity and openness of comics and encourages teachers and students to explore this in the classroom. For example, an article for teachers published on the Education World website on 1 November 2004 explains how comics can be used to teach inferencing and other comprehension skills by focusing on the notion of panels and gaps. These types of technique highlight the fact that both teachers and students need to remain aware that there is no single correct way to teach or study a comic, including Persepolis, just as there is no single correct way to read it.

1 http://comicsintheclassroom.net/

2 http://www.teachingcomics.org/ 
Many teachers may, therefore, welcome additional support to help them to teach Persepolis because the text deals with complex social and political issues, and is presented in a format which some may not be used to using in an educational context. This should not present a major problem. There are already many excellent resources for teachers wishing to discover more about the potential to use graphic novels in the classroom, as well as a number which deal specifically with Persepolis, but do these deal adequately with all the concerns of CPS? While it is extremely difficult to clearly establish the reason for the removal of Persepolis from Chicago schools from the documentation produced directly after this event, it would appear that the primary stimulus was the depiction of torture scenes within the book.

The apparently controversial scenes of torture, reproduced on many blogs and websites discussing the book's removal from Chicago schools, are drawn in the same plain, unadorned style which is used throughout Persepolis. They are striking, and sobering, but not immediately repellent in the way that a photograph of acts of torture might be. Here, as elsewhere, the reader needs to do work themselves to fully appreciate the horror. One of the key features of comics, especially one drawn in a less realistic style such as Persepolis, is that the individual reader needs to fill the gaps to complete the story suggested by the author. This means that each reader is able to do this in a way which is manageable for them, rather than being presented with a horrific image, which may be acceptable for some readers, but distressing for others. For example, the ways in which adults and children fill the gaps left in such cases may differ greatly, as may the ways in which those with experiences of the type of events described complete the story, compared to those with only second hand knowledge.

It therefore seems that the removal of Persepolis was, primarily, a reaction to the images presented, rather than the written text. It was the 'graphic' element of this novel which appeared to be of greatest concern to CPS. The relative importance of text and image in comics has been long debated. While some commentators privilege the text, others, such as Groensteen (2007), appear to give priority to the image, arguing that much of the meaning is made in response to the image. McCloud (1994) differentiates between pictures, which are 'received information' and writing which is 'perceived', taking time and specialist 
knowledge to decode. However, he also points out that when pictures become more abstracted from 'reality', as in the case of Satrapi's (2008) illustrations, "they require greater levels of perception" and thus become, "more like words" (McCloud, 1994, 49). In this case, the act to remove the book appeared to be made in response to the images from a single page of the book, rather than in response to images in a narrative sequence which is so crucial to the understanding of comics. This reaction is akin to objections to a single word or passage in a novel which has frequently led to censorship regardless of the overall message of the book. One recent example of this phenomenon was an objection the use of "nigger" in Mark Twain's Adventures of Tom Sawyer and Huckleberry Finn as reported on The Guardian newspaper website on 5 January 2011. Taken out of context, a word, phrase or image, can take on a different meaning to that likely to be attributed to it when considered as part of a whole text. Viewed as a component of the narrative of Persepolis, the images of torture take on a different significance from that which might result from merely skimming through the book and glancing at the page. Within the narrative, we see the place of these scenes in Marji's growing understanding of the political situation in her country and of her family's role in this struggle.

It is not surprising to discover that a number of lesson plans and related support materials aimed at teachers wishing to use Persepolis with students have already been produced. Most of these types of resources have been created and shared by practising teachers, based on their own experiences of teaching Persepolis. One example is A Webquest on Iran (Spangler, 2010) ${ }^{3}$ which guides students through research into various aspects of the history, society and culture of Iran. The US Institute for Library and Information Literacy Education ${ }^{4}$ also offers a lesson plan for a similar activity. In both cases, students are encouraged to investigate aspects of life in Iran for themselves. In both these examples,

3 http://www.readwritethink.org/classroom-resources/lesson-plans/gainingbackground-graphic-novel-1063.html?tab=4\#tabs

4 http://www.ilile.org/instructionalRes/LP/plans/LA-RA-reading\%20process $\% 20$ concepts $\% 20$ of $\% 20$ print, $\% 20$ comprehension $\% 20$ strategies $\% 20 \& \% 20$ self $\% 20$ monitoring.html 
students are initially directed to particular websites, but are encouraged to explore a range of viewpoints, for example, US newspaper sites, the Iran Chamber Society ${ }^{5}$ and posts by Iranian bloggers. An up-to-date teaching resource of this type, aimed at seventh grade students may be extremely helpful and welcomed by teachers as it saves them preparation time and suggests new resources and approaches, but whether this is a requirement which needs to be in place before teachers are permitted to teach Persepolis is much more questionable.

\section{Conclusion}

While Persepolis is widely accepted to be a suitable work for teenagers, as demonstrated by its frequent inclusion in guides to teaching graphic novels and comics (for example, Richards \& Williams, 2012; Scherr, 2013), it does undoubtedly contain many complex and potentially distressing themes which younger readers may want to discuss with an adult. Providing young people with an opportunity to study these types of texts in environments where they can seek clarification or explanation if required has previously been argued to be valuable for student (McNicol, 2006). For this reason, it is important that Persepolis is available to be introduced within the classroom, as well as being available to students in informal settings.

Undoubtedly, many teachers would welcome additional support to teach this novel effectively; this might include both resources to explain the political and social context of the book, and more general suggestions to assist with the teaching of graphic novels, for example, through practising teachers sharing ideas which they have devised and tested in their classrooms. It is important that any resources which are provided are politically neutral, or offer a balance of different viewpoints, and display an understanding of the unique features of graphic novels, for example, the notion of 'gaps' and the role of the reader as an active participant who works with the author to construct the text. However, access to Persepolis in schools should not depend upon the availability of these types of resources. Teachers are expected to deliver many other, equally complex, novels and do this successfully without a requirement for special

5 http://www.iranchamber.com/index.php 
support. The fact that additional resources for teachers may be helpful does not justify the removal of a text from schools.

Teachers, and head teachers, may also benefit from guidance, backed by professional organisations such as teacher unions, emphasising the pedagogical value of comics in general, and of particular titles, which will help them to respond to potential challenges such as those described in this article. It is noteworthy that Chicago school libraries rejected the call for censorship by reference to library collection development policy. Similar resources for teachers and head teachers, allowing them to present a clear case to justify the availability of texts within the classroom may give schools greater confidence in confronting attempts to censor materials.

Perhaps what this incident points to most tellingly, however, is the need for support materials not just for teachers and students, but also for educational administrators. Examining the documentation available, the public officials involved in this case appear to have, not only a lack of confidence in teachers' ability to work with comics in the classroom, but also a very limited understanding of the graphic novel format and a poor awareness of existing resources to support teachers in this area. Those in positions with the power to withdraw books from schools, thereby denying access to thousands of young people, have a duty to ensure that their actions are proportionate and justified, based on a thorough understanding of young people's literature in general; teaching methods and resources to support the use of classroom texts; and also the particular characteristics of different resource formats, including comics.

Word count: 5,176 


\section{References}

Aiken, K. G. 2010. "Superhero History: Using Comic Books to Teach U.S. History". OAH Magazine of History. 24(2): 41-47.

Allen, C. 1988. "Louise Rosenblatt and Theories of Reader-response". Reader 20: 32-9.

American Library Association (ALA). 2013. Intellectual Freedom and Censorship Q \& A. ALA. Accessed 12 July. http://www.ala.org/Template.cfm?

Section=basics\&Template $=/$ ContentManagement/ContentDisplay.cfm\&ContentID $=60610 \#$ ifpoint3

Brenner, R. 2006. “Graphic Novels 101: FAQ". Horn Book Magazine, 82 (2): 123125.

Chute, H. (2011). 'Comics Form and Narrative Lives'. Profession 2011: 107-117.

Chute, H. 2008. "Comics as Literature? Reading Graphic Narrative". Publications of the Modern Language Association of America (PMLA) 123(2): 452-65.

Eisner, W. 1985 Comics and Sequential Art. Paramus, NJ: Poorhouse Press.

El Refaie, E. (2010) "Subjective time in David B's graphic memoir 'Epileptic'". Studies in Comics 1(2): 281-299.

Gerde, V. W., and R. Spencer Foster. 2007. "X-Men Ethics: Using Comic Books to Teach Business Ethics". Journal of Business Ethics 77: 245-58. doi:

10.1007/s10551-006-9347-3

Groensteen, T. 2007. The System of Comics. Jackson: University Press of Mississippi.

Hall, K. J. and B. Lucal. 1999. "Tapping into Parallel Universes: Using Superhero Comic Books in Sociology Courses." Teaching Sociology 27:60-6.

Hammond, H. 2009. Graphic novels and multimodal literacy: a reader response study. Köln, Germany: Lambert Academic Publishers.

Hatfield, C. 2005. Alternative Comics: An Emerging Literature. Jackson MS: University of Mississippi.

Hosler, J. and K. B. Boomer. 2011. "Are Comic Books an Effective Way to Engage Nonmajors in Learning and Appreciating Science?" CBE Life Science Education 10(3): 309-317.

Hutchinson, K. H. 1949. "An Experiment in the Use of Comics as Instructional Material". 
Journal of Educational Sociology, 23 (4). 236-245.

Iser, W. 1989. Prospecting: From Reader Response to Literary Anthropology. Baltimore: John Hopkins University Press.

McCloud, S. (1994) Understanding Comics: The invisible art. New York: Harper Collins.

McNicol, S. 2006. Teenagers, Reading and Censorship: Teenagers' Views on Censorship in Libraries. http://www.ebase.bcu.ac.uk/docs/censorship-teenagefocus-groups-report.pdf.

McNicol, S. 2005. Censorship Practices and Access to Information: Interviews with School and Children's Librarians.

http://www.ebase.bcu.ac.uk/docs/Censorship_Practies_Report.doc

McNicol, Sarah and Weaver, Simon (2013) “'Dude! You mean you've never eaten a peanut butter and jelly sandwich?!?' Nut Allergy as Stigma in Comic Books". Health Communication, 28(3): 217-25.

Morrison, G. (2011). Supergods. New York: Spiegal and Grau.

Pustz, M. 1999. Comic Book Culture: Fanboys and True Believers. Jackson, MS: University Press of Mississippi.

Richards, J. and Williams, C.M. 2012. "Performing the Veil: Gender and Resistance in Marjane Satrapi's Persepolis and Shirin Neshat's Photography". Teaching Comics and Graphic Narratives: Essays on Theory, Strategy and Practice. Ed. Lan Dong. Jefferson, NC \& London: McFarland.

Rosenblatt, L. M. 1994. The Reader, Text, the Poem: The Transactional Theory of the Literary Work. Carbondale, IL: Southern Illinois University Press.

Satrapi, M. 2008. Persepolis: The Story of a Childhood and The Story of a Return. London: Vintage.

Scherr, R. 2013. "Autobiographical Comics and the Ethics of Readership." In Graphic Novels and Comics in the Classroom: Essays on the Educational Power of Sequential Art. Edited by Carrye Kay Syma and Robert G. Weiner, 134-44. Jefferson: McFarland \& Co.Inc.

Spangler, S. 2010. “Voices from the Field: Building Prior Knowledge and Exploding Stereotypes:

A Persepolis WebQuest". Journal of Media Literacy Education, 2(1): 5 - 74. 
Tilley, C.L. 2013. "Using Comics to Teach Language Arts in the 1940s and 1950s." In Graphic Novels and Comics in the Classroom: Essays on the Educational Power of Sequential Art. Edited by Carrye Kay Syma and Robert G. Weiner, 12-22. Jefferson: McFarland \& Co.Inc.

Tilley, C.L. 2012. "Seducing the Innocent: Fredric Wertham and the Falsifications that Helped Condemn Comics". Information \& Culture: A Journal of History, 47(4): 383-413.

Weiner, R.G. and Syma, C.K. 2013. “Introduction" In Graphic Novels and Comics in the Classroom: Essays on the Educational Power of Sequential Art. Edited by Carrye Kay Syma and Robert G. Weiner, 1-10. Jefferson: McFarland \& Co.Inc.

Weiner, S. 2003. Faster Than a Speeding Bullet: The Rise of the Graphic Novel. New York: Nantier, Beal, Minoustchine. 